\title{
Neuronal sphingosine kinase 2 subcellular localization is altered in Alzheimer's disease brain
}

\author{
Gaëlle Dominguez ${ }^{1}$, Marie-Lise Maddelein², Mélanie Pucelle ${ }^{3}, Y_{v a n}$ Nicaise $^{4}$, Claude-Alain Maurage ${ }^{5,6}$, \\ Charles Duyckaerts ${ }^{7}$, Olivier Cuvillier ${ }^{2+}$ and Marie-Bernadette Delisle ${ }^{1,3,4^{*}+}$ [D
}

\begin{abstract}
Background: Alzheimer's disease (AD) is characterized by the accumulation of $\beta$-amyloid (A $\beta$ ) peptides and hyperphosphorylated tau protein accompanied by neuronal loss. A $\beta$ accumulation has been associated with an impaired sphingosine 1-phosphate (S1P) metabolism. S1P is generated by sphingosine kinases (SphKs), of which there are two isoenzymes SphK1 and SphK2, and degraded by the sphingosine 1-phosphate lyase (SPL). We previously reported, that both a decrease in SphK1 expression and an increase in SPL expression, correlated with amyloid deposits in the entorhinal cortex of AD brains, suggesting a global loss of pro-survival S1P in AD neurons. SphK2 contribution has also been examined in AD yielding to conflicting results that may reflect the complexity of SphK2 regulation. The subcellular localization of SphK2, hence the compartmentalization of generated S1P, is recognized to play a crucial role in dictating either its pro-survival or pro-apoptotic functions. We therefore aimed at studying the expression of SphK2 and notably its subcellular localization in brain tissues from patients with AD.

Results: We report that a decrease in SphK2 protein cytosolic expression correlated with the density of amyloid deposits in a cohort of 25 post-mortem brains. Interestingly, we observed that the equilibrium between cytoplasmic and nuclear SphK2 is disrupted and showed that SphK2 is preferentially localized in the nucleus in AD brain extracts as compared to control extracts, with a marked increase of cleaved SphK2.
\end{abstract}

Conclusions: Our results suggest that a shift in the subcellular localization of the S1P generating SphK2 may compromise the well established pro-survival cytosolic S1P by favoring the production of nuclear S1P associated with adverse effects in AD pathogenesis.

Keywords: Alzheimer's disease, Neuropathology, $\beta$-amyloid, Sphingolipids, Sphingosine kinase 2, Sphingosine 1-phosphate

\section{Introduction}

Alzheimer's disease (AD) currently affects over 46 million people in the world and this number is estimated to reach 73 million by 2030 [54]. Gaining a better understanding of the disease is therefore critical to develop efficient treatments. AD is characterized by two paramount lesions: i) intracellular accumulation of hyperphosphorylated Tau protein forming neurofibrillary tangles (NFT) and neuropil threads; and ii) extracellular deposits of $\beta$-amyloid $(\mathrm{A} \beta)$

\footnotetext{
* Correspondence: delisle.b@chu-toulouse.fr; olivier.cuvillier@inserm.fr ${ }^{\dagger}$ Equal contributors

'Université de Toulouse, Inserm UMR 1214, 31000 Toulouse, France

${ }^{3} \mathrm{CHU}$ de Toulouse, Laboratoire de Neuropathologie, 31059 Toulouse, France Full list of author information is available at the end of the article
}

peptide, leading to both diffuse and neuritic plaques. These lesions are associated with neuronal loss, inflammatory process and synaptic dysfunction $[16,17]$. The regions affected by both lesions are hierarchically involved. Initially confined to specific locations, frontal and entorhinal cortex, hippocampus, the lesions progressively involve most areas of the brain defining stages in the disease $[6,50]$.

Sphingolipids are ubiquitous lipid components of membranes that are metabolized to form signaling molecules associated with cellular activities important for health and disease. Evidences are accumulating to argue on their key role in neurodegeneration $[9,28]$. One of 
the most important of these metabolites is sphingosine 1-phosphate (S1P), which is involved in the onset or the progression of pathological conditions including cancer, autoimmunity, cardiovascular conditions or diabetes [37]. The S1P content in cells is low and is kept under control through a delicately regulated balance between its synthesis and its degradation. The balance between the intracellular levels of S1P and its metabolic precursors, ceramide and sphingosine, has been suggested to be a switch determining whether a cell proliferates or dies [14]. S1P is generated by sphingosine kinases (SphKs), of which there are two isoenzymes (SphK1 and SphK2), and is degraded by the S1P lyase (SPL) to hexadecenal and ethanolamine phosphate [44]. Once produced, S1P can work as an intracellular signaling molecule or be secreted to act as an autocrine or paracrine molecule by binding to five specific high-affinity $\mathrm{G}$ protein-coupled receptors (GPCR), named S1P 1-5 [13, 45, 46]. Subcellular localization of SphK1 and SphK2 isoenzymes and subsequent compartimentalization of generated S1P appear to be crucial in dictating the biological effect of S1P [40]. It is well established that in order for SphK1 to mediate pro-proliferative and prosurvival signaling, it must relocalize from the cytoplasm to the plasma membrane. In contrast, the subcellular localization of SphK2 appears to be much more complex, like its biological effects [40]. For instance, when present in the nuclei, SphK2 has been associated with DNA synthesis inhibition [27] or HDAC regulation [24]. In the mitochondria, SphK2 cooperates with Bak and Bax to promote apoptosis [10]. In response to serum deprivation or cell density, SphK2 can also localize in the endoplasmic reticulum (ER) to produce S1P that can fuel a sphingolipid 'salvage' pathway, resulting in generated pro-apoptotic ceramide [34]. Two isoforms of SphK2 have been described [33, 42]. The best characterized short isoform (SphK2a or SphK2-S) is the one to which literature refers unless otherwise specified. The large isoform (SphK2b or SphK2-L) is not expressed in mice, and appears the predominant form in several human cell lines and tissues. SphK2b may be the more important in human physiologically [42].

In $\mathrm{AD}$, a deregulation of the sphingolipid metabolism was originally shown in brain samples from AD patients and age-matched normal individuals, with reduced levels of S1P, together with elevated ceramide [26]. Cellular studies showed an alteration of the ceramide/S1P balance where $A \beta$ treatment of neuronal [21] or glial [30] cells was associated with apoptosis caused by enhanced ceramide production or decreased protective S1P production. We further showed that a decrease of SphK1, S1P1 receptor expression together with an increased SPL expression in neurons were correlated to $A \beta$ deposits in entorhinal cortex from human AD brains [8].
In line with these results, Couttas and coworkers showed that loss of activity of SphK1 and SphK2 was correlated with progression of AD lesions (Braak stages) [12]. The role of SphK2 particularly in AD remains controversial. While some authors showed a decrease of activity of SphK2 in temporal cortex and hippocampus [12], others reported an increase of SphK2 activity in the frontal cortex [49] of human AD brains.

Therefore, the involvement of SphK2 in AD processes needs further explorations. It could depend on deregulation of its expression or subcellular localization. To answer the question about SphK2 implication in the deleterious effects of $A \beta$ in $A D$, we used brain tissues from patients with AD. We herein report for the first time that SphK2 expression is inversely associated with the density of amyloid deposits in frontal and hippocampal area of brains from AD patients and demonstrated a shift of SphK2 from the cytosol to the nucleus in AD neurons, accompanied by a marked increase of cleaved SphK2 in the AD brain.

\section{Materials and methods Validation of anti-SphK2 antibody}

E. coli BL21 strains were transformed by one of the pJ414 constructs - PET21 vectors expressing either SphK1 (403AA) or SphK2 (674AA) with an HIS tag. Forty $\mathrm{ml}$ of an overnight pre-culture of transformants grown at $37{ }^{\circ} \mathrm{C}$ in DYT medium supplemented with kanamycin $(100 \mu \mathrm{g} / \mathrm{ml})$ was used to inoculate $200 \mathrm{ml}$ of DYT-KAN media. After $2 \mathrm{~h}$ of growth at $37{ }^{\circ} \mathrm{C}$, SphK proteins expression was induced by $5 \mathrm{mM}$ of Isopropyl $\beta$-D-1-thiogalactopyranoside (IPTG). Aliquots of the cultures were made $5 \mathrm{~h}$ after induction. Protein expression was confirmed by western blot analysis with mouse antihistidine (Cusabio, Ref. CSB-MA000011M0m). The specificity of the anti-SphK2CT rabbit polyclonal antibody (Sigma, Ref. SAB4502433) was confirmed by western blot.

\section{Human brain tissues}

Paraffin embedded human brain tissues were provided by certified French biological resource centers from Lille (Neurobank Lille DC-2008-642) and Toulouse (Brain bank AC-2009-973) for immunohistochemistry and immunofluorescence studies. For western blot studies, human brain frozen tissues were provided by the national brain bank GIE Neuro-CEB (AC-2007-5) and the biological resource center of $\mathrm{CHU}$ Toulouse (Brain bank AC-2009-973). The utilization of postmortem material was approved by the corresponding biobank ethic committees. All cases were scored according to current criteria of NIA-Alzheimer's Association [39]. The assessment included Braak and Thal neuropathology stages $[5,50]$. 


\section{Immunohistochemistry}

Post-mortem tissues from 25 AD patients were included in the immunohistochemical study. Characteristics of patients (age, gender, post mortem interval, Braak and Thal stages) are summarized in Table 1. Hemi-brains were fixed with formalin (4\% in PBS) during approximately 1 month. Paraffin-embedded, formalin-fixed sections $(4 \mu \mathrm{m})$ from frontal cortex and hippocampal area (entorhinal cortex and hippocampus) were deparaffinized in xylene and rehydrated in ethanol. Antigen retrieval was performed by immersing sections in boiling EDTA buffer ( $\mathrm{pH}$ 9.0). Endogenous peroxidase and alkaline phosphatase were blocked by incubation of the sections for $5 \mathrm{~min}$ in Dual Endogenous Enzyme Block (Dako, Denmark). Sections were initially incubated with a primary antibody directed against $\beta$-amyloid (Dako, mouse clone 6 F/3D, Ref. M0872, 1:100) during $3 \mathrm{~h}$ at room temperature (RT). Sections were washed twice during 7 min in Tris-buffered $\mathrm{NaCl}$ solution with Tween 20 ( $\mathrm{pH}$ 7.6, Dako). Immunostaining was revealed using BrightVision poly HRP-Anti-Mouse IgG (Immunologic, Netherlands) during $30 \mathrm{~min}$ at RT and treated with diaminobenzidine/hydrogen peroxide (DAB, Dako) for $5 \mathrm{~min}$. After this first step, sections were washed for 10 min with Tris buffer saline (pH 7.6, Dako) before incubation with a primary rabbit polyclonal antibody directed against SphK2 (Sigma, Ref. SAB4502433, 1:50) overnight at $4{ }^{\circ} \mathrm{C}$. The sections were washed twice during $7 \mathrm{~min}$ in Tris buffer saline (pH 7.6, Dako). Immunostaining was exposed using BrightVision poly AP-anti-

Table 1 Characteristics of patients included in the immunohistochemistry study

\begin{tabular}{ll}
\hline Variables & $\mathrm{AD}(n=25)$ \\
\hline Age at death (years) & \\
Median [IQR] & $51.0[73.0-87.0]$ \\
Range & $18(72)$ \\
Female gender, $\mathrm{n}(\%)$ & \\
Post mosterm interval & $21.0[9.0-27.0]$ \\
Median [IQR] & $3.0-96.0$ \\
Range & \\
"A" Thal - $\mathrm{n}$ of patients (\%) & $21(84)$ \\
3 (4 and 5) & $3(12)$ \\
2 (3) & $1(4)$ \\
1 (1 and 2) & $0(0)$ \\
0 (None) & \\
"B" Braak Stage - $n$ of patients (\%) & $24(96)$ \\
3 (V and VI) & $1(4)$ \\
2 (III and IV) & $0(0)$ \\
1 (I and II) & $0(0)$ \\
\hline
\end{tabular}

Rabbit IgG (Immunologic) during $45 \mathrm{~min}$ at $\mathrm{RT}$ and treated with Liquid Fast Red (Abcam) for $30 \mathrm{~min}$. Sections were counterstained with hematoxylin then mounted in Faramount Aqueous Mounting Medium (Dako). Once mounted, slides were scanned with a digital scanner NanoZoomer (Hamamatsu, Ref. [2].0-RS: C10730-13) to obtain high resolution virtual slides. Digitalized slides were analyzed with an imaging analysis system (Image ${ }^{\circ}$ ). Morphometric investigations were carried out by a semi-automatic procedure on ImageJ. The number of neurons expressing SphK2, the percentage of $\mathrm{A} \beta$ stained surface and the number of amyloid deposits were quantified among the different cortical layers of the frontal and entorhinal cortex as well as in the CA1. Columns constituted of contiguous microscopic fields, from the pial surface to the white matter were drawn on each slide. As the fields were examined at a magnification of $\times 400$, each field was $300 \mu \mathrm{M} \times 150 \mu \mathrm{M}$ in size. As the thickness of the cortex appeared to be variable between the different sections, after the counting step, the columns were standardized to 10 fields $[8,18]$. For cortical areas, field 1 corresponded to the cortex immediately under the pial surface and field 10 reached the white matter (Additional file 1). In each field, the number of neurons expressing a negative and a positive $\mathrm{SphK} 2$ stain were counted. Moreover, the number of $A \beta$ focal deposits and the percentage of surface labeled by amyloid per field were determined and were reported on a database.

\section{Preparation of human brain total homogenates}

Fresh samples from frontal cortex and hippocampal area of $10 \mathrm{AD}$ cases and 6 age-matched controls were used. No significant differences in sex and post-mortem interval were noted between $\mathrm{AD}$ patients and the control group. There was a difference in the age medians. As expected, AD patients had significantly higher Braak and Thal stages than the control group (Table 2). Samples of hippocampal area contained both entorhinal cortex and Ammon's horn (including CA1). Moreover randomly selected samples of cerebellum from of $\mathrm{AD}(n=5)$ and control $(n=3)$ were included as the cerebellar tissue exhibits a weak density of $A \beta$ deposits even in the late phase of disease [50]. Frozen tissue samples were processed with Precellys ${ }^{\circ}$ homogenizer and CK14 lysing kit (Bertin Instruments, Paris, France) containing lysis buffer (50 mM Tris- $\mathrm{HCl} \mathrm{pH}$ 8.0, 5\% SDS, $0.25 \mathrm{M}$ saccharose, $200 \mathrm{mM} \mathrm{NaCl}$ and EDTA-free protease inhibitor cocktail). Samples were sonicated at $4{ }^{\circ} \mathrm{C}$ then centrifuged at $13000 \mathrm{~g}$ for $10 \mathrm{~min}$.

\section{Preparation of nuclei-enriched fractions and cytoplasm- enriched fraction}

The same cases except one control $(\mathrm{AD}=10$, Control $=5)$ were included in this experiment. Frozen tissue samples 
Table 2 Characteristics of patients included in the western blot study

\begin{tabular}{lll}
\hline Variables & Controls $(\mathrm{n}=6)$ & $\mathrm{AD}(\mathrm{n}=10)$ \\
\hline Age at death (years) & & $P$-value \\
Median [IQR] & $74.0[70.5-80.0]$ & $81.0[78.0-85.0]$ \\
Range & $67.0-86.0$ & $62.0-89.0$ \\
Female gender, $\mathrm{n}(\%)$ & $2(33.3)$ & $5(55.5)$ \\
Post mosterm interval & & \\
Median [IQR] & $17.5[12.0-22.0]$ & $8[7.5-23.0]$ \\
Range & $4.0-36.0$ & $6.0-50.0$ \\
Missing (n) & 1 & 0 \\
"A" Thal - $\mathrm{n}$ of patients (\%) & & \\
3 (4 and 5) & $0(0)$ & $8(80)$ \\
2 (3) & $0(0)$ & $1(10)$ \\
1 (1 and 2) & $1(16.7)$ & $1(10)$ \\
0 (None) & $5(83.3)$ & $0(0)$ \\
"B" Braak Stage - $\mathrm{n}$ of patients (\%) & & $10(100)$ \\
3 (V and VI) & $0(0)$ & $0(0)$ \\
2 (III and IV) & $0(0)$ & $0(0)$ \\
1 (I and II) & $5(83.3)$ & $0(0)$ \\
0 (None) & $1(16.7)$ & 0.001 \\
\hline
\end{tabular}

were lysed as aforementioned in HEPES buffer ( $\mathrm{pH} 7.4$ ) (20 mM HEPES, $10 \mathrm{mM} \mathrm{KCl,} 2 \mathrm{mM} \mathrm{MgCl}$, $1 \mathrm{mM}$ EDTA, $0.25 \mathrm{M}$ saccharose, and EDTA-free protease inhibitor cocktail). Nuclei-enriched fractions and cytoplasmicenriched fractions were prepared by sequential centrifugation. Nuclei were pelleted by centrifugation (500 $\mathrm{g}$ for $10 \mathrm{~min}$ at $4{ }^{\circ} \mathrm{C}$ ) then sonicated at $4{ }^{\circ} \mathrm{C}$ and centrifuged at $9000 \mathrm{~g}$ for $30 \mathrm{~min}$, in Tris buffer ( $\mathrm{pH} 7.4)(50 \mathrm{mM}$ Tris$\mathrm{HCl}, 250 \mathrm{mM} \mathrm{NaCl}, 1 \mathrm{mM}$ EDTA, 0.1\% Triton and EDTA-free protease inhibitor cocktail). Supernatants were removed, and the membrane and cytoplasmic fractions were separated by centrifugation at 16,000 g (30 min at $4{ }^{\circ} \mathrm{C}$ ). Isolation of nuclear and cytosolic fractions was confirmed by western blot with primary antibodies directed against rabbit polyclonal PARP (GeneTex, Ref. GTX100573, 1:1000) and rabbit polyclonal LDH (GeneTex, Ref. GTX114525, 1:10,000).

\section{Western blot}

Total protein concentration was assessed on the supernatant with the BCA Protein Assay (Interchim). Samples were heated at $95{ }^{\circ} \mathrm{C}$ for $5 \mathrm{~min}$ with $5 \% \beta$-mercaptoethanol, $0.05 \%$ bromophenol blue. $150 \mu \mathrm{g}$ of total proteins were loaded by lane in precast gels with Stain-Free technology (4-15\% Mini-PROTEAN ${ }^{\circledR}$ TGX Stain-Free ${ }^{\mathrm{TM}}$, Ref. 456-8083). The proteins were separated by electrophoresis at $90 \mathrm{~V}$ in a MiniProtean Tetra System (BioRad Laboratories, Irvine, CA). After migration and semidry transfer (Transblot Turbo, Bio-Rad), nitrocellulose membranes were blocked with 5\% skimmed milk, and washed 3 times with Tris-buffered saline buffer containing $0.05 \%$ Tween-20 (TBST). Blots were probed with a primary antibody directed against rabbit polyclonal SphK2 (Sigma, Ref. SAB4502433, 1:500) and $\beta$-amyloid (Sigma, Ref. A8354, 1:1000). After an overnight incubation at $4{ }^{\circ} \mathrm{C}$, the membranes were washed with TBST, labeled with a peroxidase-conjugated anti-rabbit (dilution 1:3000) secondary antibody (Bio-Rad) and revealed by chemiluminescence (Clarity kit, Bio-Rad). Bands were quantified by densitometry with ImageLab (Bio-Rad) software. The density of total protein, detected by UV light, was used to normalize the signals [20, 23].

\section{Immunofluorescence}

Post-mortem tissues from $9 \mathrm{AD}$ and 6 controls were included in the immunofluorescence study (Table 3). There were no significant differences in age, sex and post mortem interval between the groups used for the immunofluorescence study. Most of the AD subjects were staged Braak V-VI and Thal 4 to 5 . Control subjects included cases with respectively low Braak (I-II) or Thal (1-2) stages. Immunofluorescent staining of SphK2 and MAP2 was performed on paraffin-embedded, formalin-fixed human brain sections. The human brain sections were deparaffinized in xylene and rehydrated in ethanol. Antigen retrieval was performed by immersing sections in boiling EDTA buffer ( $\mathrm{pH}$ 9.0). Human brain sections were washed in PBS, permeabilized with PBSTriton $0.1 \%$ for $10 \mathrm{~min}$. To avoid the autofluorescence, sections were incubated in True black 1X (Ozyme) for 
Table 3 Characteristics of patients included in the immunofluorescence study

\begin{tabular}{|c|c|c|c|}
\hline Variables & Controls $(n=6)$ & $A D(n=9)$ & $P$-value \\
\hline \multicolumn{4}{|l|}{ Age at death (years) } \\
\hline Median [IQR] & $70.0[68.0-73.0]$ & $81.0[72.0-85.0]$ & NS \\
\hline Range & $58.0-82.0$ & $69.0-88.0$ & \\
\hline Female gender, $\mathrm{n}(\%)$ & $2(33.3)$ & $5(50.0)$ & NS \\
\hline \multicolumn{4}{|l|}{ Post mosterm interval } \\
\hline Median [IQR] & $10.0[5.5-23.0]$ & $24.5[16.0-29.0]$ & NS \\
\hline Range & $5.0-24.0$ & $8.0-44.0$ & \\
\hline “A" Thal - n of patients (\%) & & & $<0.001$ \\
\hline 3 (4 and 5) & $0(0)$ & $8(88.9)$ & \\
\hline $2(3)$ & $0(0)$ & $1(11.1)$ & \\
\hline 1 (1 and 2) & $4(66.7)$ & $0(0)$ & \\
\hline 0 (None) & $2(33.3)$ & $0(0)$ & \\
\hline "B" Braak Stage - n of patients (\%) & & & $<0.001$ \\
\hline $3(\mathrm{~V}$ and $\mathrm{VI})$ & $0(0)$ & $9(100)$ & \\
\hline 2 (III and IV) & $1(16.7)$ & $0(0)$ & \\
\hline 1 (I and II) & $3(50)$ & $0(0)$ & \\
\hline 0 (None) & $2(33.3)$ & $0(0)$ & \\
\hline
\end{tabular}

1 min. Nonspecific antibody reactions were blocked by incubation in solution containing 5\% BSA for $1 \mathrm{~h}$. Sections were incubated with mouse monoclonal primary anti-MAP2 (Life technologies, Ref. MA512826, 1:100) and anti-SphK2 (Sigma, Ref. SAB4502433, 1:50) antibodies. Secondary antibodies included goat anti-rabbit IgG (Life technologies, Alexa Fluor 543 conjugate, Ref. A-11010, 1:1000) and labeled goat anti-mouse IgG (Life technologies, Alexa Fluor ${ }^{\odot} 488$, Ref. A-11001, 1:1000). DAPI was used as a nuclear counterstain (final concentration of $1 \mu \mathrm{g} / \mathrm{mL}$ ). It also allowed to visualize the amyloid deposits (Additional file 2). Human brain sections were mounted with Fluorescence mounting medium (DAKO S3023). Confocal laser microscopy was performed on a Zeiss, LSM 780 apparatus. Several fields of view ( $>300$ cells) were analyzed for each group. The confocal composite image (merge) was analyzed using Image 1.510 software. Morphometric investigations were carried out to quantify the percentage of surface stained by SphK2 antibody. SphK2 staining in neurons was estimated on the total surface of each neuron, using a staining threshold taking into account the background. The percentage of SphK2 stained surface was further analyzed in two cell compartments leading to a ratio of nuclear versus cytoplasmic stained surfaces. The same nuclear/cytoplasmic ratio was applied for analysis of intensity of SphK2 staining. To overcome experimental biases, the percentage of colocalization between MAP2 and SphK2 and the percentage of colocalization between DAPI and SphK2 were determined.

\section{Data analysis}

Statistical analysis was carried out with a multilevel linear mixed model to take into account non independent data. For cortical area, due to the poor representativeness of fields 1 (non tissular zone and pial surface) and 10 (proximal white matter), these fields were not included in statistical analysis. To avoid experimental bias related to the number of neurons per field, the immunohistochemistry data were expressed as percentage of variation relative to the total number neurons. For correlation analyses, the Spearman's correlation coefficient, $\mathrm{R}$, was determined. Correlations were estimated as significant at $p<0.05$. Comparisons between groups were analyzed using oneway analyses of variance (ANOVAs). Statistical analyses were performed using the Statview 5.0 software.

\section{Results}

SphK2 antibody is specific for SphK2 and does not crossreact with the SphK1 isoenzyme

We used a rabbit polyclonal SphK2 antibody raised against amino acid 580-629 sequence. The western blots carried out on SphK1 and SphK2 recombinant proteins and on human brain lysate, confirmed the specificity of the antibody for SphK2 recombinant protein with no cross-reaction for the SphK1 isoenzyme (Fig. 1a2). No other bands were observed with SphK2 antibody in whole control brain lysate.

\section{Immunohistochemical studies}

Most of the subjects presented a high number of neurofibrillary tangles as well as of amyloid deposits (Braak V- 


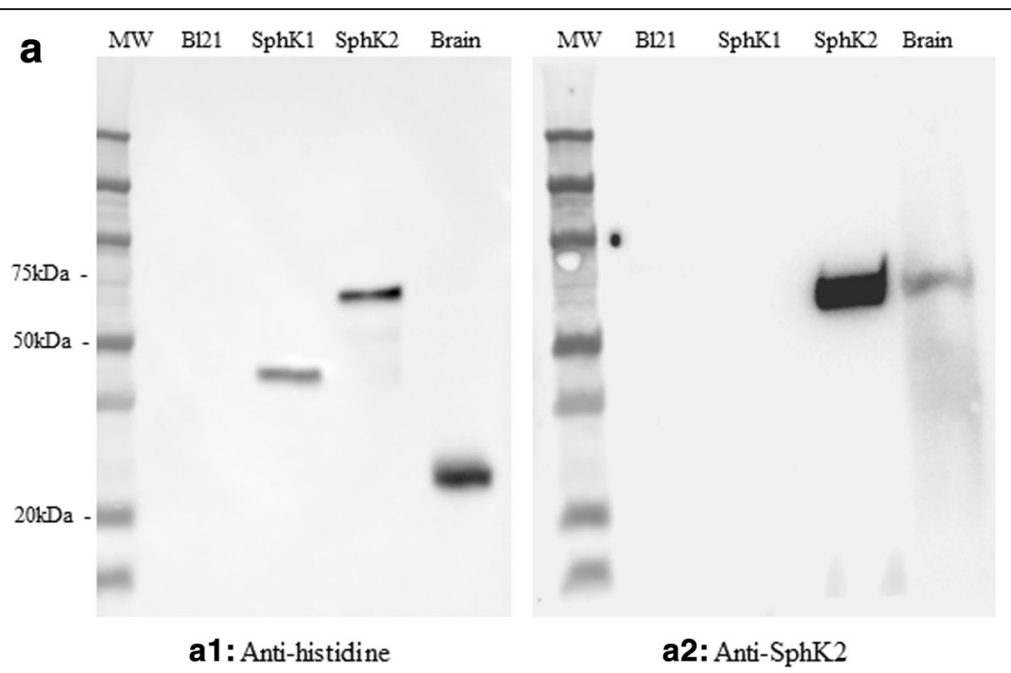

Fig. 1 Validation of anti-SphK2 antibody. Escherichia coli strain BL21 overexpressing His-tagged full length SphK1, His-tagged full length SphK2, and human brain lysate were analyzed by Western blotting using anti-Histidine (a1) and anti-SphK2 antibodies (a2)

VI and Thal 4 to 5; Table 1). In both studied cortical areas, thickness variability was noticed and could be related to atrophy, which is a common feature in AD. The $\mathrm{A} \beta$ deposits were more frequent in cortical layers II and III, mostly represented in fields 2 to 6 (Additional file 3). There was no correlation between the density of neurons and $\mathrm{A} \beta$ deposits (in three locations, $p>0.5$ for all regressions), whether $A \beta$ deposits were evaluated as the number of focal deposits or the percentage of amyloid areas ( $p>0.5$ for all regressions). SphK2 staining was mainly observed in neurons (Fig. 2a), and likely in the nucleus of cells exhibiting the hallmarks (size, shape, specific location) of oligodendrocytes. SphK2 staining was also observed less frequently in astrocytes. In neurons, the immunostaining of SphK2 was both nuclear and cytoplasmic. Because the nuclear immunostaining of SphK2 was difficult to quantify, our analysis focused on cytoplasmic SphK2 expression to avoid experimental bias. The cytoplasmic SphK2 expression was heterogeneous between the three analyzed structures $\left(\mathrm{F}_{(2,647)}=350.8, p\right.$ $<0.0001$ ). The percentage of SphK2 positive neurons was higher in CA1 (vs frontal or entorhinal cortex, p $<0.0001$ for both comparisons) and lower in frontal vs entorhinal cortex $(\mathrm{p}<0.0001)$.

\section{Negative correlation between amyloid deposits and the percentage of SphK2 positive neurons in AD brain}

The percentage of SphK2 positive neurons (cytoplasm) was inversely correlated with the amount of amyloid deposits (A $\beta$ surface percentage) in the frontal cortex $(r=$ 0.037, $p=0.007$; Fig. 2b1), in the entorhinal cortex $(r=0$. 062, $p<0.001$; Fig. 2b2) and in CA1 $(r=0.29, \mathrm{p}<0.001$; Fig. 2b3). This negative correlation was also found for the focal plaques (frontal cortex: $r=0.044, p=0.003$; entorhinal cortex: $r=0.064, \mathrm{p}<0.001$; and CA1: $r=0$. 38, $\mathrm{p}<0.001$; Fig. 2c). From the coefficient values, we noted that the relationship between the amount of amyloid and the percentage of SphK2 positive neurons was stronger in the CA1 area than in the cortical regions (frontal and entorhinal).

\section{Frontal cortex and hippocampal AD brain extracts show high amyloid content}

The amount of $A \beta$ was assessed in human brain lysates from the frontal cortex, hippocampal area (entorhinal cortex and CA1) in AD and control groups. To better appreciate the relation between SphK2 and A $\beta$ deposits, we analyzed samples of cerebellum, a brain area where $\mathrm{A} \beta$ deposits are scarce and appear late in the evolution of the disease [50] (Fig. 3a, top row). Western blot studies revealed the presence of the $\beta$-amyloid precursor protein (APP, approximately $130 \mathrm{kDa}$ band) along with a set of apparent supramolecular $A \beta$ assemblies. Highmolecular weight $A \beta$ oligomers or multiples of trimeric $\mathrm{A} \beta$ oligomers have been previously characterized in human AD brain tissue [32, 51]. Quantitative analyses did not demonstrate significant differences between control and AD groups for APP $(p>0.5)$.

In addition to $150-250 \mathrm{kDa}$ bands corresponding to higher MW A $\beta$ oligomers, bands of $27 \mathrm{kDa}$ were detected. This molecular masses apparently correspond to multiples of trimeric $A \beta$ and could thus represent hexameric $(A \beta * 27) A \beta$ assemblies. High levels of total $A \beta$ (high MW oligomers and $A \beta * 27$ ) were observed in $A D$ group in comparison with the control group $\left(\mathrm{F}_{(1,38)}=10\right.$. $7 ; p=0.002)$. When each structure was considered separately (Fig. 3b), statistical analysis revealed a significant increase of total $A \beta$ in frontal cortex $(p=0.009)$ and an 


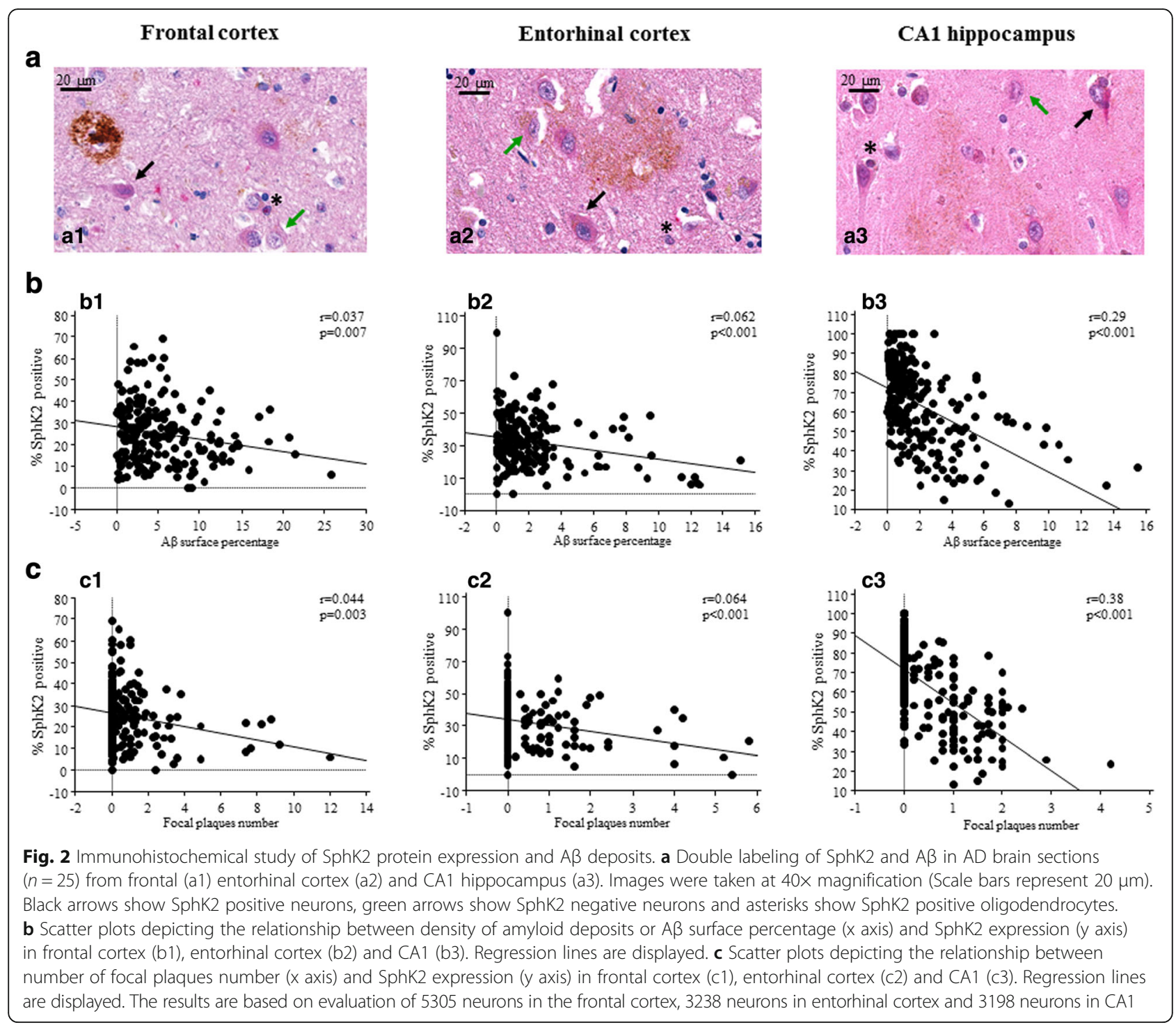

increase at the margin of statistical significance in the hippocampal area $(p=0.06)$. No difference was found in the cerebellum $(\mathrm{p}>0.5)$.

With regard to the $A \beta^{*} 27$ oligomers, there was a significant difference between groups $\left(\mathrm{F}_{(1,38)}=7.9 ; p=0.008\right)$, with a significant increase in hippocampal area $(p=0.028$; Fig. 3c) and an increase in the frontal to the margin of the significance $(p=0.08)$. No difference was found in cerebel$\operatorname{lum}(p=0.99)$.

Higher MW A $\beta$ oligomers $\left(\mathrm{F}_{(1,38)}=8.6 ; p=0.006\right)$ content were markedly increased in frontal cortex $(\mathrm{p}=0.02)$ but not significantly in hippocampal area $(p=0.095)$ and in the cerebellum $(p=0.4)$, in $\mathrm{AD}$ group (data not shown).

These data are in accordance with the evolution of $A \beta$ deposits and the distinct sequences in which the regions of the brain are hierarchically involved according to the Thal stages (Phase 1: neocortical A $\beta$ deposits, Phase 2: hippocampal area deposits, Phase 5: cerebellum is the latest structure affected by $\mathrm{A} \beta$ deposits) [50].

\section{Specific increased expression of a cleaved SphK2 form in AD brains}

The SphK2 immunoblots showed two major bands in brain lysates, a $75 \mathrm{kDa}$ band corresponding to the large isoform of SphK2 (SphK2b) and a protein of lower molecular weight which was considered as a cleaved fragment of SphK2 (Fig. 3a, low row). A cleaved fragment of SphK2 has been previously described in extraneural cell models (Jurkat $\mathrm{T}$ cells, murine fibroblasts, spleen cells) in relation to apoptotic process [53].

The quantification of total SphK2 (full length and cleaved forms) revealed an increase of its expression in $\mathrm{AD}$ samples, in frontal cortex $\left(\mathrm{F}_{(1,14)}=5.4 ; p=0.04\right)$ but not in the hippocampal area and cerebellum $(p>0.5$ for both comparisons). However, full length SphK2 was not different 


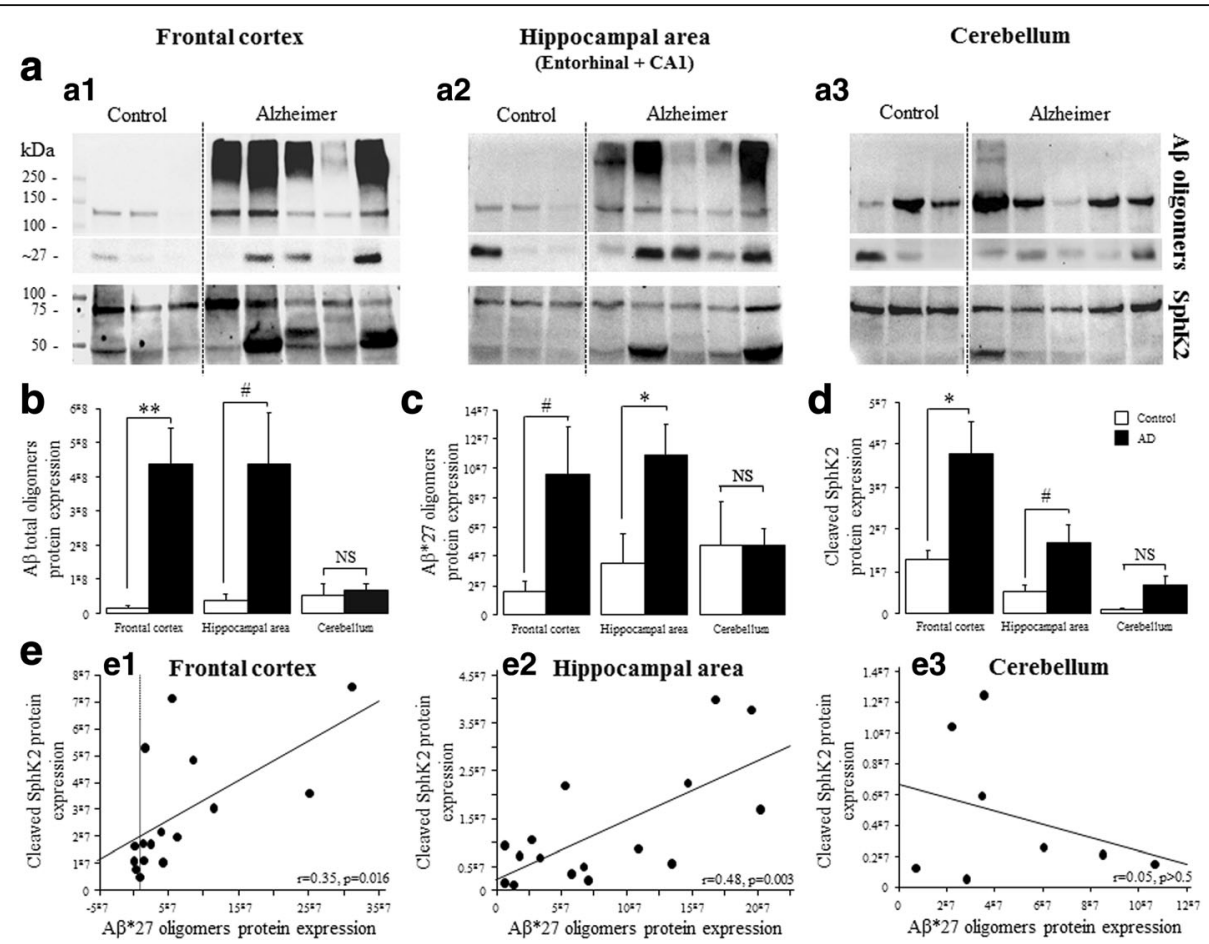

Fig. 3 Correlation between the proportion of cleaved SphK2 and A $\beta^{*} 27$ oligomers in frontal cortex, hippocampal area and cerebellum. a Representative blot showing A oligomers (upper panel) and SphK2 (lower panel) full length and cleaved proteins in frontal cortex (a1), hippocampal area (entorhinal cortex and (A1) (a2) and cerebellum (a3) tissue samples. A $\beta$ oligomers and SphK2 expression were normalized using stain-free imaging technology. The relative abundance of total $A \beta$ oligomers $(\mathbf{b})$ and $A \beta^{*} 27$ oligomers $(\mathbf{c})$ was analyzed in the three structures. $\mathbf{d}$ Cleaved SphK2 expression, in control $(n=6)$ and $\operatorname{AD}(n=10)$ groups in frontal cortex, hippocampal area and cerebellum (control $n=3$ and $A D n=5$ ). Statistical significance was determined using one-way ANOVA. Columns, mean; bars, SEM. ${ }^{*} p<0.05,{ }^{* *} p<0.01$, \# $p<0.08$ vs control group. e Scatter plots depicting the relationship between $A \beta^{*} 27$ oligomers ( $x$ axis) and cleaved SphK2 expression (y axis) in frontal cortex (e1), hippocampal area (e2) and cerebellum (c3). Regression lines are displayed

between $\mathrm{AD}$ and control groups (data not shown) $(p>0$. 05). In contrast, the cleaved SphK2 fragments (Fig. 3d) was higher in $\mathrm{AD}$ extracts as compared to control $\left(\mathrm{F}_{(1,38)}=7.6\right.$; $p=0.009$ ). More specifically, an increase was observed in the frontal cortex $\left(\mathrm{F}_{(1,14)}=5.8 ; p=0.03\right)$ and in the hippocampal area, to the margin of the significance $\left(\mathrm{F}_{(1,14)}=4.1\right.$; $p=0.06)$. No difference was found in cerebellum $(p>0.08)$.

Correlation analyses were made to confirm relationships between individual expression of a cleaved SphK2 form and $A \beta$ levels (Fig. 3e). The individual expression of cleaved SphK2 form correlated positively with $A \beta * 27$ levels in frontal cortex $(r=0.35, p=0.016$; Fig. 3e1) and in hippocampal area $(r=0.48, p=0.003$; Fig. 3e2), but not in cerebellum ( $\mathrm{p}>0.5$; Fig. 3e3).

A positive correlation was also noted between higher MW A $\beta$ oligomers and cleaved SphK2 in frontal cortex $(r$ $=0.47, \mathrm{p}=0.003)$ and in hippocampal area $(r=0.73, p=0$. 001) (data not shown). In the cerebellum, higher MW $A \beta$ oligomers were expressed at a low level in one AD case (Fig. 3a3). Cleaved SphK2 was also found in this case.

The subcellular localization of SphK2 is altered in AD brains To analyze the subcellular localization of both full length and cleaved SphK2, cytoplasmic- and nuclei-enriched fractions were prepared from frontal cortex and hippocampal area. In line with data presented in Fig. 3, the cleaved SphK2 expression was markedly increased in AD samples when compared to controls $\left(\mathrm{F}_{(1,58)}=5.7 ; p=0\right.$. 02; Fig. 4a) (data not shown).

The quantification of total SphK2 (full length and cleaved forms) revealed a differential expression between the two subcellular fractions in control group $\left(\mathrm{F}_{(1,18)}=\right.$ $12.9 ; p=0.002)$. SphK2 was less expressed in the nucleienriched fraction $\left(1.22^{\mathrm{E}} 8 \pm 0.23^{\mathrm{E}} 8\right.$ densitometry units) than in the cytoplasmic-enriched fraction $\left(2.47^{\mathrm{E}} 8 \pm 0\right.$. $25^{\mathrm{E}} 8$ densitometry units). This difference was found in the frontal cortex $(p=0.04)$ and in the hippocampal area $(p=0.01)$. In $\mathrm{AD}$ group $\left(\mathrm{F}_{(1,38)}=0.35 ; p=0.5\right)$, no difference was found between the nuclear $\left(2.75^{\mathrm{E}} 8 \pm 0\right.$. $63^{\mathrm{E}} 8$ densitometry units) and the cytoplasmic $\left(3.22^{\mathrm{E}} 8 \pm\right.$ $0.48^{\mathrm{E}} 8$ densitometry units) (data not shown).

For each subcellular fraction, we analyzed separately full length and cleaved SphK2 fragments in AD group as compared to control. The results are expressed as percentage variation in $\mathrm{AD}$ versus control group (Fig. 4b and $\mathrm{c}$ ).

Full length SphK2 expression was increased in the nuclei enriched fraction $\left(\mathrm{F}_{(1,28)}=3.9 ; p=0.050\right)$ but was 


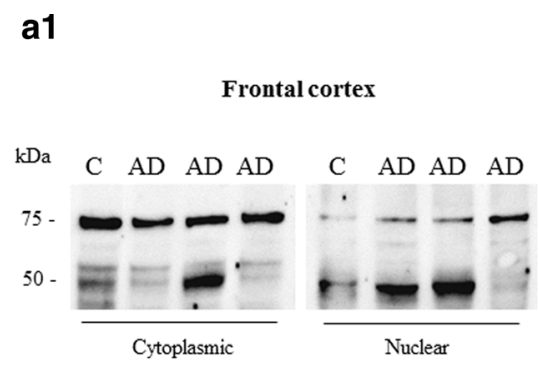

a2

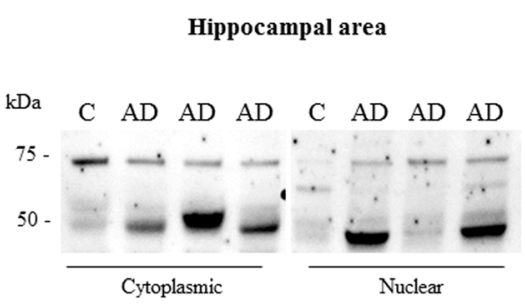

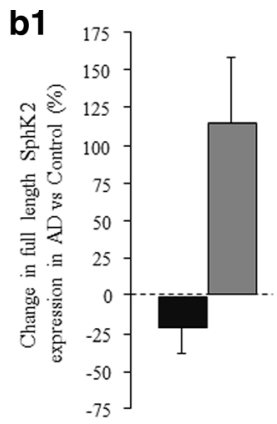

b2

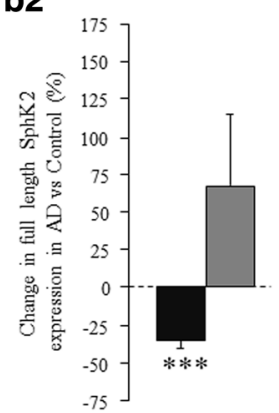

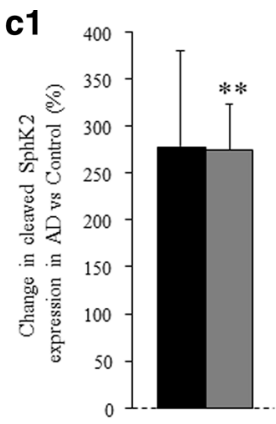

c2

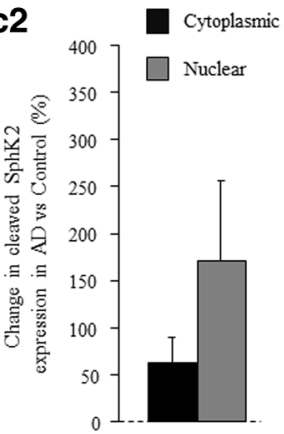

Fig. 4 SphK2 protein expression is increased in nuclear compartments in AD group. Subcellular localization of both full length and cleaved SphK2 was analyzed by western blot. a Representative western blot showing SphK2 expression in cytoplasmic and in nuclear fraction of control ( $n=5)$ or AD groups ( $n=10)$ of tissue samples from the frontal cortex (a1) or the hippocampal area (a2). Relative expression of full length SphK2 (b) and cleaved SphK2 (c) proteins in cytoplasmic or nuclear fractions was analyzed in the frontal cortex (b1-c1) and the hippocampal area (b2-c2) of tissue extracts in AD group as compared to control group. After normalization (using stain-free imaging technology), data were expressed as percentage of SphK2 expression levels in AD versus control group. Statistical significance was determined using one-way ANOVA test. Columns, mean; bars, SEM. ${ }^{* *} p<0.01,{ }^{* *} p<0.001$ vs control group

decreased in cytoplasmic enriched fraction $\left(\mathrm{F}_{(1,28)}=5.4 ; p\right.$ $=0.027$ ) in $\mathrm{AD}$ group relative to the control (Fig. $4 \mathrm{~b}$ ). Post-hoc analyses showed a reduction of cytoplasmic full length SphK2 mainly in the hippocampal area $(p<0.001)$.

A rise of cleaved SphK2 (Fig. 4c) was observed in nuclear fractions $\left(\mathrm{F}_{(1,28)}=10.4 ; p=0.003\right)$ and in cytoplasmic fractions $\left(\mathrm{F}_{(1,28)}=3.9 ; \mathrm{p}=0.050\right)$ in $\mathrm{AD}$ group relative to control group especially in frontal cortex (nuclear $p=0.0015$ et cytoplasmic $p=0.08$; Fig. 4c1). To a lesser extent, yet not significantly, this change of expression was seen in hippocampal area (nuclear $p=0.17$ and cytoplasmic $p=0.13$; Fig. 4c2).

These data suggest a shift of full length SphK2 from cytosol to the nucleus examined in all brain structures, accompanied by an accumulation of the cleaved SphK2 in the nucleus that would be more significant in the frontal cortex, in AD.

\section{Immunofluorescence study shows that SphK2 is preferentially localized in the nucleus}

The density of neurons and of amyloid deposits were inversely correlated in the frontal $(r=0.14, p=0.0004)$ and entorhinal cortex $(r=0.15, p=0.002)$, but not in the CA1 $(r=0.02, p=0.25)$. This negative correlation was only related to the presence of focal deposits in all structure (frontal cortex: $r=0.13, p=0.0006$, entorhinal cortex: $\mathrm{r}=0$. 13, $p=0.0045$, CA1: $r=0.11, p=0.005$ ) (data not shown).

We first examined the distribution of SphK2 in the frontal cortex, entorhinal cortex and CA1 then its subcellular localization. With SphK2 immunostaining both full length and cleaved fragments were stained. The immunostaining of SphK2 was mainly seen in neurons and oligodendrocytes (Fig. 5a). In neurons, SphK2 was essentially seen in the nucleus in AD contrary to the control group in which SphK2 was mostly expressed in the cytosol (intensity: $p<0.001$; neuron area (\%): $\mathrm{p}<0.001$ for both comparisons). At regional level, SphK2 was not homogeneous (intensity: $\mathrm{F}_{(2,704)}=8.9 ; p=0.05$; neuron area $\left.(\%): \mathrm{F}_{(2,704)}=5.5 ; \mathrm{p}=0.005\right)$. Indeed, SphK2 was more expressed in the CA1 (intensity: $p=0.026$ vs frontal cortex, $\mathrm{p}=\mathrm{NS}$ vs entorhinal; neuron area (\%): $\mathrm{p}$ $=0.05$ vs frontal cortex, $p=0.001$ vs entorhinal) (data not shown) as compared to both cortical regions.

In agreement with data shown in Fig. 2, immunofluoresence microscopy revealed that the percentage of SphK2 stained surface in neuron (nuclear and cytoplasmic compartments) was decreased $\left(\mathrm{F}_{(1,837)}=49.0 ; p<0\right.$. 0001; Fig. $5 \mathrm{~b}$ ) in the AD group as compared to control for all structures (frontal cortex: $p=0.033$; entorhinal cortex and CA1: $\mathrm{p}<0.0001)$. The nuclear/cytoplasmic ratio of 


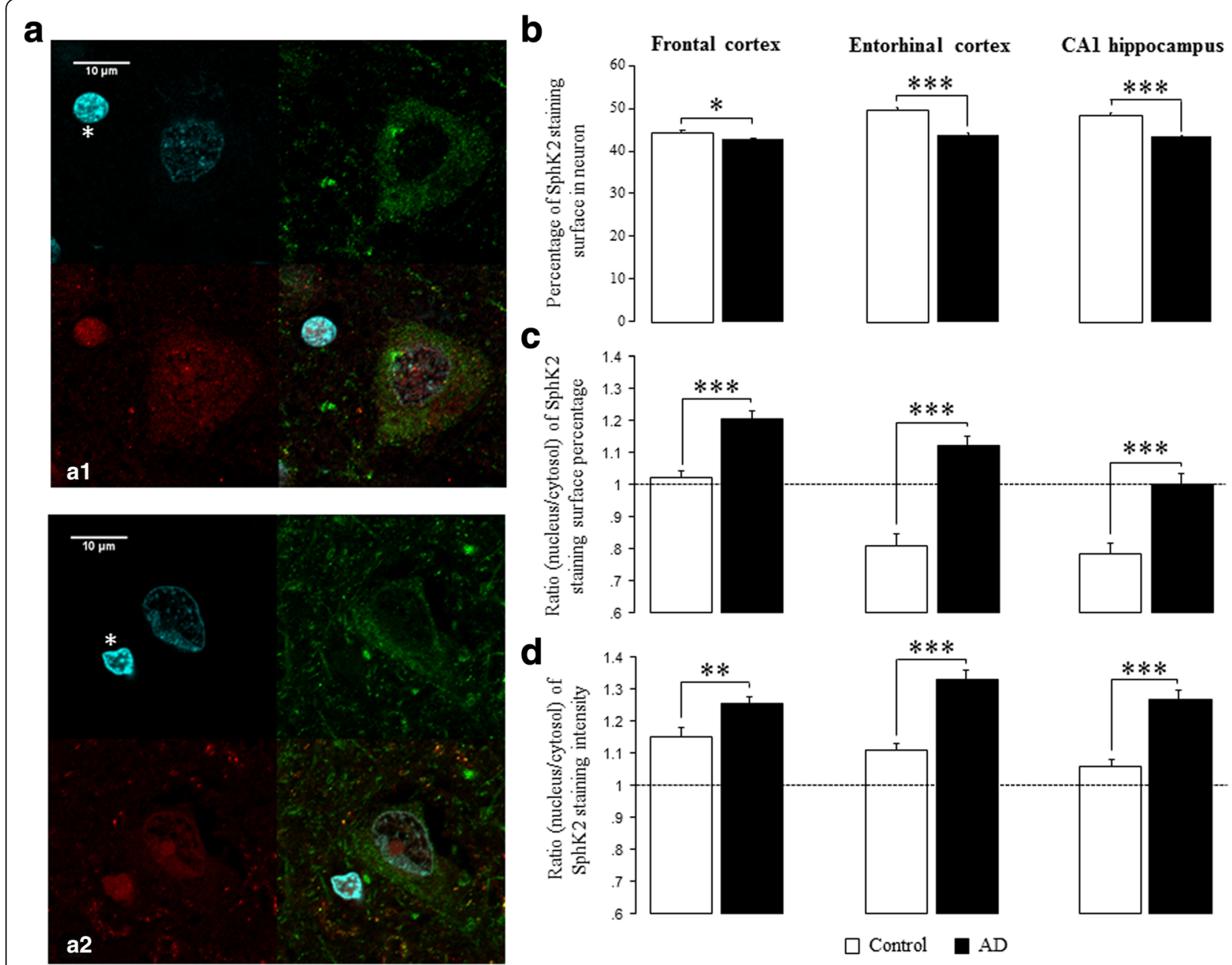

Fig. 5 Disruption of SphK2 localization within neurons in AD brain. a Representative confocal micrographs of SphK2 subcellular localization in fixed human frontal cortex tissue, in control $(a 1 ; n=6)$ and $A D(a 2 ; n=9)$ groups. Images were taken at $63 \times$ magnification (Scale bars indicate $10 \mu \mathrm{m}$ ). A TRITC-conjugated secondary antibody was used for SphK2 (red) and a FITC-conjugated secondary antibody was used for MAP2 (green). Nuclei were stained with DAPI (cyan). The confocal composite image (merge) was analyzed using ImageJ 1.510 software. The results are based on the evaluation of 493 neurons in AD group (frontal cortex: 187; entorhinal cortex: 150; CA1: 156) and 346 neurons in control group (frontal cortex: 133; entorhinal cortex: 90; CA1: 123). SphK2 staining was mainly observed in neurons and oligodendrocytes (asterisk). In neurons, the immunostaining of SphK2 was both nuclear and cytoplasmic. $\mathbf{b}$ Percentage of SphK2 staining surface was quantified in neurons. c SphK2 staining ratio between nuclear and cytoplasmic surface (\%) in control and AD neurons for the three areas. $\mathbf{d}$ SphK2 staining intensity ratio (nuclear/cytoplasmic) in control and AD neurons for the three areas. Columns, mean; bars, SEM ${ }^{*} p<0.05,{ }^{* *} p<0.01,{ }^{* * *} p<0.001$ vs control

SphK2 stained surface was increased in AD group $\left(\mathrm{F}_{(1,837)}\right.$ $=113.5 ; \mathrm{p}<0.0001)$. This change of expression was seen in the frontal cortex, the entorhinal cortex and the CA1 ( $p<0.001$ for all comparisons) as compared to the control subjects, demonstrating a disturbance of the SphK2 subcellular localization (Fig. 5c). This observation was reinforced by the increase of SphK2 nuclear/cytoplasmic ratio of staining intensity in $\mathrm{AD}$ group, for the three structures ( $p \leq 0.001$ for the three structures) (Fig. 5d).

\section{Discussion}

A deregulation of sphingolipid metabolism and more particularly S1P signaling has been recently stressed in
$\mathrm{AD}$ (reviewed in $[7,9,28,38,52])$. Initial work in neuronal cell models showed that apoptosis induced by $\mathrm{A} \beta$ peptide was dependent on increased production of proapoptotic ceramide [30] or decreased activity of SphK1 leading to decreased content of pro-survival S1P [21]. This deregulation of the ceramide/S1P balance with increase in ceramide and decrease in S1P was seen in patients to correlate with the level of $A \beta$ peptide and phosphorylated tau [26]. More recently, two independent studies established an alteration of S1P metabolism with a decrease in SphK1 or SphK2 expression and enzymatic activity and increase in S1P lyase, the enzyme that degrades S1P $[8,12]$. Again, enzymatic deregulation 
leading to decreased S1P correlated with $\mathrm{A} \beta$ deposits and progression of $\mathrm{AD}$ lesions $[8,12]$.

Besides the likely role for SphK1 isoform, SphK2 deregulation may contribute more significantly to $\mathrm{AD}$ lesions and progression. Indeed, SphK2 was found as the predominant isoenzyme in the rodent brain [3, 31, 33], and SphK2 activity and mRNA levels are considerably higher than that of SphK1 [3, 12]. Using mice with germline knockout of SphK2, it was recently shown that SphK2 is responsible to the largest part for S1P synthesis in the brain [31]. As aforementioned, the role of SphK2 has been examined in $\mathrm{AD}$ patients yet the results remain so far controversial. If a decrease in S1P level was linked to the reduction of SphK2 activity in the hippocampus and the temporal cortex [12], an increase of SphK2 activity has been reported in the frontal cortex [49]. These ambiguous results may simply reflect the complexity of SphK2 regulation and function. Depending on its subcellular compartment, SphK2 can generate S1P that will favor cell death or proliferation and survival [40].

Until now, the lack of commercial SphK2 antibodies validated for western blotting and immunohistochemistry has remained a drawback for a better understanding of the specific functions of SphK2. In this study, we used a SphK2 antibody raised against the C-terminal sequence of SphK2, the specificity of which for the SphK2 isoenzyme was confirmed using human SphK1 and SphK2 recombinant proteins.

We herein report that a decrease in cytoplasmic SphK2 protein expression correlates with the density of amyloid deposits in $\mathrm{AD}$ brains. Interestingly, we observed that the equilibrium between cytoplasmic and nuclear SphK2 was disrupted and showed that SphK2 is preferentially localized in the nucleus in AD brain extracts as compared to control extracts, with a marked increase of cleaved SphK2.

More precisely, we showed that cytoplasmic expression of SphK2 in neurons was inversely correlated to $A \beta$ deposits, whatever their type (diffuse or focal) in the CA1 and to a lesser extent in the frontal and entorhinal cortex. This is in keeping with our previous results on SphK1 cytoplasmic expression, which was also negatively correlated to the density of $A \beta$ deposit [8], suggesting the involvement of both isoenzymes in the deregulation of this signaling pathway. Western blot analyses corroborated the absence of variation of SphK2 expression in whole brain lysates of $\mathrm{AD}$ patients when compared to control brains as previously reported $[8,49]$. Cieslik et al., using PC12 cells, similarly showed that exposure to $A \beta_{1-42}$ had no effect on SphK2 [11]. These results showing an absence of variation of total SphK2 at both cellular and tissular levels suggest there could be a change in subcellular localization of SphK2 without any alteration of its total expression. As a matter of fact, both nuclei- enriched and the cytoplasmic-enriched fractions showed an alteration of SphK2 expression with a loss of expression in cytoplasm accompanied with an increased expression in nucleus in hippocampal area and to a lesser extent in frontal cortex. Immunofluorescence studies confirmed that nuclear and cytoplasmic expressions of SphK2 were modified in favor of a cytoplasmic decrease and a nuclear increase expression in AD brains.

Taking advantage of an antibody directed against the Cterminal portion of SphK2, the presence of a low molecular weight protein $(\sim 50 \mathrm{kDa})$ could be detected on immunoblots. This form matches with the truncated fragment of SphK2 cleaved by caspase- 1 at the level of the D138 according to Weigert et al., and online software ExPASy (PeptideCutter) [53]. In this truncated fragment, all the domains of SphK2 are preserved including the catalytic domain and the ligand binding domain, suggesting that cleaved SphK2 could preserve its enzymatic activity. Its distribution in both compartments is in agreement with theoretical predictions based on online software WoLF PSORT 20, which establishes that cleaved SphK2 could be localized in both cytoplasmic and nuclear compartments. Caspase-1-mediated cleavage of SphK2, by removing the nuclear localization signal (NLS), would prevent the entry in the nucleus of a cytosolic cleaved SphK2. This is in favor of a cleavage of SphK2 in the nucleus. Actually, it has been reported that inactivated caspase- 1 can be translocated to the nucleus and processed into an active form in parallel with apoptosis [35]. Our data show that an increase of cleaved SphK2 in AD group correlated positively with the amount of amyloid oligomers, particularly in hippocampus and in entorhinal cortex. Yet, the significance and function of such cleaved SphK2 requires further interrogation.

Similar to SphK1, SphK2 has a pro-survival effect when localized in the cytoplasm from where it can be targeted to the plasma membrane to produce S1P, which can be then secreted to exert autocrine and paracrine effect through its specific receptors [40]. Thus, our results suggest that, during $\mathrm{AD}$, there is a decrease in the prosurvival cytoplasmic SphK2 similar to previous findings showing a decrease in pro-survival cytoplasmic SphK1 $[8,12]$. We also previously reported that S1P receptor subtype 1 was decreased in AD [8] and recent data suggest that pharmacological agonists of S1P1 (FTY720, SEW2871) can improve cognitive function in AD rat model $[1,2]$. Collectively, these data indicate that cytosolic SphK1/SphK2 signaling and potential subsequent S1P receptor signaling could be linked to a pro-survival role of $\mathrm{S} 1 \mathrm{P}$ in $\mathrm{AD}$ pathogenesis, and that strategies aimed at rescuing impaired cytosolic SphK1/SphK2 signaling could be beneficial for patients.

The nuclear SphK2 signaling appears much more complex. It could be deleterious in $\mathrm{AD}$ pathogenesis. 
Interestingly, in cancer models, retinoic acid signaling was found to be deregulated by nuclear SphK2/S1P signaling, with S1P acting as an antagonist for the retinoic acid receptor (RAR) beta [47, 48]. Retinoic acid represents an antioxidant that can affect cognition [4, 43]. More specifically, retinoic acid can modulate the hippocampus-dependent memory influencing the neuronal plasticity (changes in synaptic strength, numbers of synapses and neurons) [36]. The disruption of retinoid signaling has been implicated in the pathogenesis of $A D$ [22]. The expressions of genes that are engaged in the production of $A \beta$ including $\beta$-secretase enzyme (BACE), presenilin 1 or presenilin 2 are regulated by retinoids $[29,41]$. Finally, the protective role of retinoic acid in the pathogenesis of AD has been demonstrated in transgenic APP/PS1 mouse model. Indeed, its prolonged administration produced a reduction of amyloid deposits and lead to an improvement of memory [15]. Thus, the disruption of acid retinoic signaling by the nuclear SphK2/S1P signaling may have an implication of neurodegenerative processes in $\mathrm{AD}$ and in the memory disorders. On the other hand, nuclear SphK2 may have a beneficial effect via its role in epigenetic regulation, on synaptic plasticity and memory processes. Indeed, the nuclear S1P produced by SphK2 inhibits histone deacetylases HDAC1/2 and regulated histone acetylation [24]. FTY720, a synthetic analog of sphingosine which is phosphorylated by nuclear $\mathrm{SphK} 2$, induced an improvement of memory process $[19,25]$ and a better survival of neuronal progenitors in hippocampus [19]. It could be hypothesized that the nuclear-localized SphK2 is involved in a compensatory attempt process to restore neuronal function.

\section{Conclusions}

The cellular functions of SphK2 are complex and the mechanism(s) that may drive the differences in its subcellular localization remain(s) largely unanswered question and will require further investigation. Similarly, future work is needed to understand the significance of the presence of cleaved SphK2 in the neuron nuclei. Nevertheless, from our findings it is reasonable to suggest that a change in the subcellular localization of the S1P generating SphK2 may compromise the wellestablished pro-survival cytosolic S1P by favoring the production of nuclear S1P associated with deleterious effects in $\mathrm{AD}$ pathogenesis.

\section{Additional files}

Additional file 1: Virtual slides and counting method. (a) Virtual slide obtained from hippocampal area section. The section is double labeled for SphK2 and A 3 . (b) Representative scale matrix designed on entorhinal cortex used for neurons and $A \beta$ deposits counting. Boxes extend from pial surface to white matter. The number of fields mainly depends on the thickness of the cortex. To compare results from different individuals, it was necessary to standardize the number of fields. Thus, after the counting step, the columns were standardized to 10 fields [18]. (TIFF $319 \mathrm{~kb}$ )

Additional file 2: Visualization of amyloid deposits was carried out using a DAPI staining. Our preliminary studies showed that DAPI stains the nuclei as well as plaques in gray matter. In order to validate that DAPI stained extracellular deposits are amyloid deposits, an immunofluorescent staining of $A \beta$ peptide was realized with a mouse primary antibody (Dako, mouse clone 6 F/3D, Ref. M0872, 1:100). Immunofluorescence study was performed on paraffin-embedded, formalin-fixed human brain sections. Secondary antibody of goat anti-mouse lgG (Life technologies, Alexa Fluor ${ }^{\circledR} 488$, Ref. A-11001, 1:1000) was used for visualization. DAPI was used as a nuclear counterstain (final concentration of $1 \mu \mathrm{g} / \mathrm{mL}$ ). The merge confocal composite image was analyzed with ImageJ 1.510 software and was confirmed the colocalization. (TIFF $284 \mathrm{~kb}$ )

Additional file 3: Percentage of amyloid area according to fields. This percentage was calculated on the whole population of 25 cases. Field 1 corresponded to the cortex immediately under the pial surface and field 10 reached the white matter. Due to the poor representativeness of fields 1 (non tissular zone and pial surface) and 10 (proximal white matter), they were not included in statistical analysis for the cortical areas. The distribution of cortical layers was consistent with previously reported morphological studies ([18]; [17]). For instance, in frontal and entorhinal cortices, the cortical layer I was principally found in fields 1 and 2, cortical layers II and III were mostly represented in fields 2 to 6 , layer IV was confined in fields 6 to 8 , and layers V and VI were found in fields 7 to 10 . Moreover, the $A \beta$ deposits were more frequent in cortical layers II and III. As the fields were examined at a magnification of $\times 400$, each field was $300 \mu \mathrm{M} \times 150 \mu \mathrm{M}$ in size. (TIFF $35 \mathrm{~kb}$ )

\section{Acknowledgements}

This research was supported by a grant from the association France Alzheimer (grant no. SM2015\#345). G. Dominguez was supported by this grant. The authors would like to thank Dr. Johnatan Ceccom, Dr. Christian Touriol, Pr Emmanuelle Uro-Coste and Pr Jean-Michel Senard as well as his team for their advices and assistance and Lorenne Robert, Najat Loukh, Celia Martron and Serge Estaque for technical assistance. They are grateful to Dr. Pascal Demange for generous gift of reagents: PERT21 vectors expressing either SphK1 or SphK2. The authors would like to thank Sabrina LeclereTurbant and Marie-Claire Artaud-Botté from the GiE Neuro-CEB as well as Lille Neurobank. They are grateful to Maryline Calise for administrative help. They acknowledge the Cellular Imaging Facility Rangueil-I2MC/TRI Plateform (confocal microscopy) and the CMEAB-Rangueil Medicine Faculty/TRI Plateform (virtual slides).

\section{Funding}

All sources of funding for the research reported should be declared. The role of the funding body in the design of the study and collection, analysis, and interpretation of data and in writing the manuscript should be declared.

\section{Authors' contributions}

GD and YN carried out double labeling immunoassays and immunoblot experiments and participated in drafting the manuscript. GD and MBD performed statistical analysis and data interpretation. MP and GD carried out immunofluorescence experiment and analyzed data. MLM carried out immunoblot experiment, analyzed data and participated in the draft of the manuscript. CAM and CD provided paraffin embedded material and associated data for staging, advices in the conception of used methodology, participated in drafting and reviewing the manuscript. GD, MLM, OC and MBD conceptualized the design of the study, analyzed and interpreted data, and wrote the manuscript. All authors read and approved the final manuscript.

\section{Ethics approval and consent to participate}

The study was approved by the corresponding Brain Banks' committees (Cérébrothèque/CRB CHU Toulouse NAC-2009-973, Brain Bank NeuroCEB Paris NAC-2007-5 and Neurobank Lille No DC-2008-642). In all cases, in accordance with the French Bioethical Laws, the consents were signed by the patients themselves or their next of kin in their name to permit an autopsy and neuropathological investigation. The national computerized registry of objection to autopsy was systematically consulted. The above cited Brain Banks have been 
declared at the Ministry of Higher Education and Research and have received approval to distribute samples.

\section{Consent for publication}

Written informed consent was obtained from the patient for the publication of this report and any accompanying images as required in the concerned authorized biological resource centers.

\section{Competing interests}

The authors declare that they have no competing interests.

\section{Publisher's Note}

Springer Nature remains neutral with regard to jurisdictional claims in published maps and institutional affiliations.

\section{Author details}

${ }^{1}$ Université de Toulouse, Inserm UMR 1214, 31000 Toulouse, France. ${ }^{2}$ Institut de Pharmacologie et de Biologie Structurale, Université de Toulouse, CNRS, UPS, Toulouse, France. ${ }^{3} \mathrm{CHU}$ de Toulouse, Laboratoire de Neuropathologie, 31059 Toulouse, France. ${ }^{4}$ Université de Toulouse III, Faculté de Médecine Rangueil, 31062 Toulouse, France. ${ }^{5}$ Université Lille, Inserm, UMR 837, 59000 Lille, France. ${ }^{6} \mathrm{CHU}$ Lille, Service de Pathologie, 59037 Lille, France. ${ }^{7}$ Laboratoire de Neuropathologie et Centre de Recherche de I'ICM, Hôpital de la Salpétrière, 75013 Paris, France.

\section{Received: 30 January 2018 Accepted: 19 March 2018} Published online: 03 April 2018

\section{References}

1. Asle-Rousta M, Kolahdooz Z, Oryan S, Ahmadiani A, Dargahi L (2013) FTY720 (fingolimod) attenuates beta-amyloid peptide (Aß42)-induced impairment of spatial learning and memory in rats. J Mol Neurosci 50:524-532

2. Asle-Rousta M, Oryan S, Ahmadiani A, Rahnema M (2013) Activation of sphingosine 1-phosphate receptor-1 by SEW2871 improves cognitive function in Alzheimer's disease model rats. EXCLI J 12:449-461

3. Blondeau N, Lai Y, Tyndall S, Popolo M, Topalkara K, Pru JK, Zhang L, Kim H, Liao JK, Ding K, Waeber C (2007) Distribution of sphingosine kinase activity and mRNA in rodent brain. J Neurochem 103:509-517

4. Bonhomme D, Pallet V, Dominguez G, Servant L, Henkous N, Lafenêtre $P$, Higueret P, Béracochéa D, Touyarot K (2014) Retinoic acid modulates intrahippocampal levels of corticosterone in middle-aged mice: consequences on hippocampal plasticity and contextual memory. Front Aging Neurosci 6:6

5. Braak H, Alafuzoff I, Arzberger T, Kretzschmar H, Del Tredici K (2006) Staging of Alzheimer disease-associated neurofibrillary pathology using paraffin sections and immunocytochemistry. Acta Neuropathol 112:389-404

6. Braak H, Braak E (1995) Staging of Alzheimer's disease-related neurofibrillary changes. Neurobiol Aging 16:271-278 discussion 278-284

7. Ceccom J, Delisle M-B, Cuvillier O (2014) Sphingosine 1-phosphate as a biomarker for Alzheimer's disease? Med Sci (Paris) 30:493-495

8. Ceccom J, Loukh N, Lauwers-Cances V, Touriol C, Nicaise Y, Gentil C, UroCoste E, Pitson S, Maurage CA, Duyckaerts C, Cuvillier O, Delisle M-B (2014) Reduced sphingosine kinase-1 and enhanced sphingosine 1-phosphate lyase expression demonstrate deregulated sphingosine 1-phosphate signaling in Alzheimer's disease. Acta Neuropathol Commun 2:12

9. Chakrabarti SS, Bir A, Poddar J, Sinha M, Ganguly A, Chakrabarti S (2016) Ceramide and Sphingosine-1-phosphate in cell death Pathways : relevance to the pathogenesis of Alzheimer's disease. Curr Alzheimer Res 13:1232-1248

10. Chipuk JE, McStay GP, Bharti A, Kuwana T, Clarke CJ, Siskind LJ, Obeid LM, Green DR (2012) Sphingolipid metabolism cooperates with BAK and BAX to promote the mitochondrial pathway of apoptosis. Cell 148:988-1000

11. Cieślik M, Czapski GA, Strosznajder JB (2015) The molecular mechanism of amyloid $\beta 42$ peptide toxicity: the role of sphingosine Kinase- 1 and mitochondrial Sirtuins. PLOS One 10:e0137193

12. Couttas TA, Kain N, Daniels B, Lim XY, Shepherd C, Kril J, Pickford R, Li H, Garner B, Don AS (2014) Loss of the neuroprotective factor sphingosine 1phosphate early in Alzheimer's disease pathogenesis. Acta Neuropathol Commun 2:9

13. Cuvillier O (2012) Sphingosine 1-phosphate receptors: from biology to physiopathology. Med Sci (Paris) 28:951-957
14. Cuvillier O, Pirianov G, Kleuser B, Vanek PG, Coso OA, Gutkind S, Spiegel S (1996) Suppression of ceramide-mediated programmed cell death by sphingosine-1-phosphate. Nature 381:800-803

15. Ding Y, Qiao A, Wang Z, Goodwin JS, Lee E-S, Block ML, Allsbrook M, McDonald MP, Fan G-H (2008) Retinoic acid attenuates beta-amyloid deposition and rescues memory deficits in an Alzheimer's disease transgenic mouse model. J Neurosci 28:11622-11634

16. Dorostkar MM, Zou C, Blazquez-Llorca L, Herms J (2015) Analyzing dendritic spine pathology in Alzheimer's disease: problems and opportunities. Acta Neuropathol 130:1-19

17. Duyckaerts C, Delatour B, Potier M-C (2009) Classification and basic pathology of Alzheimer disease. Acta Neuropathol 118:5-36

18. Duyckaerts C, Hauw JJ, Bastenaire F, Piette F, Poulain C, Rainsard V, JavoyAgid F, Berthaux P (1986) Laminar distribution of neocortical senile plaques in senile dementia of the Alzheimer type. Acta Neuropathol 70:249-256

19. Efstathopoulos P, Kourgiantaki A, Karali K, Sidiropoulou K, Margioris AN, Gravanis A, Charalampopoulos I (2015) Fingolimod induces neurogenesis in adult mouse hippocampus and improves contextual fear memory. Transl Psychiatry 5:e685

20. Gilda JE, Gomes AV (2013) Stain-free total protein staining is a superior loading control to $\beta$-actin for western blots. Anal Biochem 440:186-188

21. Gomez-Brouchet A, Pchejetski D, Brizuela L, Garcia V, Altié M-F, Maddelein M-L, Delisle M-B, Cuvillier O (2007) Critical role for sphingosine kinase-1 in regulating survival of neuroblastoma cells exposed to amyloid-beta peptide. Mol Pharmacol 72:341-349

22. Goodman AB (2006) Retinoid receptors, transporters, and metabolizers as therapeutic targets in late onset Alzheimer disease. J Cell Physiol 209:598-603

23. Gürtler A, Kunz N, Gomolka M, Hornhardt S, Friedl AA, McDonald K, Kohn JE, Posch A (2013) Stain-free technology as a normalization tool in western blot analysis. Anal Biochem 433:105-111

24. Hait NC, Allegood J, Maceyka M, Strub GM, Harikumar KB, Singh SK, Luo C, Marmorstein R, Kordula T, Milstien S, Spiegel S (2009) Regulation of histone acetylation in the nucleus by sphingosine-1-phosphate. Science 325: $1254-1257$

25. Hait NC, Wise LE, Allegood JC, O'Brien M, Avni D, Reeves TM, Knapp PE, Lu J, Luo C, Miles MF, Milstien S, Lichtman AH, Spiegel S (2014) Active, phosphorylated fingolimod inhibits histone deacetylases and facilitates fear extinction memory. Nat Neurosci 17:971-980. https://doi.org/10. 1038/nn.372825

26. He X, Huang Y, Li B, Gong C-X, Schuchman EH (2010) Deregulation of sphingolipid metabolism in Alzheimer's disease. Neurobiol Aging 31:398-408

27. Igarashi N, Okada T, Hayashi S, Fujita T, Jahangeer S, Nakamura S (2003) Sphingosine kinase 2 is a nuclear protein and inhibits DNA synthesis. J Biol Chem 278:46832-46839

28. Karunakaran I, van Echten-Deckert G (2017) Sphingosine 1-phosphate - a double edged sword in the brain. Biochim Biophys Acta 1859:1573-1582

29. Lee H-P, Casadesus G, Zhu X, Lee H, Perry G, Smith MA, Gustaw-Rothenberg K, Lerner A (2009) All-trans retinoic acid as a novel therapeutic strategy for Alzheimer's disease. Expert Rev Neurother 9:1615-1621

30. Lee J-T, Xu J, Lee J-M, Ku G, Han X, Yang D-I, Chen S, Hsu CY (2004) Amyloid-beta peptide induces oligodendrocyte death by activating the neutral sphingomyelinase-ceramide pathway. J Cell Biol 164:123-131

31. Lei M, Shafique A, Shang K, Couttas TA, Zhao H, Don AS, Karl T (2017) Contextual fear conditioning is enhanced in mice lacking functional sphingosine kinase 2. Behav Brain Res 333:9-16

32. Lesné SE, Sherman MA, Grant M, Kuskowski M, Schneider JA, Bennett DA, Ashe KH (2013) Brain amyloid- $\beta$ oligomers in ageing and Alzheimer's disease. Brain 136:1383-1398

33. Liu H, Sugiura M, Nava VE, Edsall LC, Kono K, Poulton S, Milstien S, Kohama T, Spiegel S (2000) Molecular cloning and functional characterization of a novel mammalian sphingosine kinase type 2 isoform. J Biol Chem 275: 19513-19520

34. Maceyka M, Sankala H, Hait NC, Le Stunff H, Liu H, Toman R, Collier C, Zhang M, Satin LS, Merrill AH, Milstien S, Spiegel S (2005) SphK1 and SphK2, sphingosine kinase isoenzymes with opposing functions in sphingolipid metabolism. J Biol Chem 280:37118-37129

35. Mao PL, Jiang Y, Wee BY, Porter AG (1998) Activation of caspase-1 in the nucleus requires nuclear translocation of pro-caspase- 1 mediated by its prodomain. J Biol Chem 273:23621-23624

36. McCaffery P, Zhang J, Crandall JE (2006) Retinoic acid signaling and function in the adult hippocampus. J Neurobiol 66:780-791 
37. Mendelson K, Evans T, Hla T (2014) Sphingosine 1-phosphate signalling. Development 141:5-9

38. Mielke MM, Lyketsos CG (2010) Alterations of the sphingolipid pathway in Alzheimer's disease: new biomarkers and treatment targets? NeuroMolecular Med 12:331-340

39. Montine TJ, Phelps CH, Beach TG, Bigio EH, Cairns NJ, Dickson DW, Duyckaerts C, Frosch MP, Masliah E, Mirra SS, Nelson PT, Schneider JA, Tha DR, Trojanowski JQ, Vinters HV, Hyman BT, National Institute on Aging, Alzheimer's Association (2012) National Institute on Aging-Alzheimer's association guidelines for the neuropathologic assessment of Alzheimer's disease: a practical approach. Acta Neuropathol 123:1-11

40. Neubauer HA, Pitson SM (2013) Roles, regulation and inhibitors of sphingosine kinase 2. FEBS J 280:5317-5336

41. Obulesu M, Dowlathabad MR, Bramhachari PV (2011) Carotenoids and Alzheimer's disease: an insight into therapeutic role of retinoids in animal models. Neurochem Int 59:535-541

42. Okada T, Ding G, Sonoda H, Kajimoto T, Haga Y, Khosrowbeygi A, Gao S, Miwa N, Jahangeer S, Nakamura S-I (2005) Involvement of N-terminalextended form of sphingosine kinase 2 in serum-dependent regulation of cell proliferation and apoptosis. J Biol Chem 280:36318-36325

43. Olson CR, Mello CV (2010) Significance of vitamin a to brain function, behavior and learning. Mol Nutr Food Res 54:489-495

44. Pitson SM (2011) Regulation of sphingosine kinase and sphingolipid signaling. Trends Biochem Sci 36:97-107

45. Rosen H, Gonzalez-Cabrera PJ, Sanna MG, Brown S (2009) Sphingosine 1phosphate receptor signaling. Annu Rev Biochem 78:743-768

46. Saba JD, Hla T (2004) Point-counterpoint of sphingosine 1-phosphate metabolism. Circ Res 94:724-734

47. Shi W-N, Cui S-X, Song Z-Y, Wang S-Q, Sun S-Y, Yu X-F, Li Y, Zhang Y-H, Gao Z-H, Qu X-J (2017) Overexpression of SphK2 contributes to ATRA resistance in colon cancer through rapid degradation of cytoplasmic RXRa by K48/ K63-linked polyubiquitination. Oncotarget 8:39605-39617

48. Sun D-F, Gao Z-H, Liu H-P, Yuan Y, Qu X-J (2012) Sphingosine 1-phosphate antagonizes the effect of all-trans retinoic acid (ATRA) in a human colon cancer cell line by modulation of RARB expression. Cancer Lett 319:182-189

49. Takasugi N, Sasaki T, Suzuki K, Osawa S, Isshiki H, Hori Y, Shimada N, Higo T, Yokoshima S, Fukuyama T, Lee VM-Y, Trojanowski JQ, Tomita T, Iwatsubo T (2011) BACE1 activity is modulated by cell-associated sphingosine-1phosphate. J Neurosci 31:6850-6857

50. Thal DR, Rüb U, Orantes M, Braak H (2002) Phases of a beta-deposition in the human brain and its relevance for the development of AD. Neurology 58:1791-1800

51. Upadhaya AR, Lungrin I, Yamaguchi H, Fändrich M, Thal DR (2012) Highmolecular weight $A \beta$ oligomers and protofibrils are the predominant $A \beta$ species in the native soluble protein fraction of the AD brain. J Cell Mol Med 16:287-295

52. van Echten-Deckert G, Hagen-Euteneuer N, Karaca I, Walter J (2014) Sphingosine-1-phosphate: boon and bane for the brain. Cell Physiol Biochem 34:148-157

53. Weigert A, Cremer S, Schmidt MV, von Knethen A, Angioni C, Geisslinger G, Brüne B (2010) Cleavage of sphingosine kinase 2 by caspase-1 provokes its release from apoptotic cells. Blood 115:3531-3540

54. World Alzheimer Report 2016 | Alzheimer's Disease International. https://www.alz.co.uk/research/world-report-2016. Accessed 4 Sep 2017.

\section{Submit your next manuscript to BioMed Central and we will help you at every step:}

- We accept pre-submission inquiries

- Our selector tool helps you to find the most relevant journal

- We provide round the clock customer support

- Convenient online submission

- Thorough peer review

- Inclusion in PubMed and all major indexing services

- Maximum visibility for your research

Submit your manuscript at www.biomedcentral.com/submit

C Biomed Central 